\title{
A Poor Substitute for Religion
}

\section{Helen Andrews}

The severity of the current outbreak of hysteria was brought home to me by how easily I had forgotten all the examples of "cancel culture" that Dr. Bolotin cites. I remember reading about the stories he mentions-the Cisco employees fired for saying “All lives matter," the Boeing executive fired for an op-ed he wrote thirty years ago-but I hadn't thought about them since they happened. In a saner era, any one of these incidents could have been a cause célèbre. In the era of Black Lives Matter, they barely had time to make an impression before the next outrageous firing hit the news and made everyone forget about yesterday's. Everyone, that is, except the victims themselves.

I am skeptical of the pundits who try to make sense of this hysteria by calling it a new religion. So often it amounts to the same glib arguments that New Atheists like Christopher Hitchens and Sam Harris made against religion, applied to “wokeness” as a particular case. John McWhorter of Columbia University has argued that wokeness is a religion because its adherents "cannot be reasoned with" and to them "anything that questions" its tenets "is simply not allowed.” McWhorter is a brilliant writer whose willingness to take unpopular stands I greatly admire, but I was alarmed when I heard him on a podcast offer, as his paradigmatic example of a religious person who "cannot be reasoned with,” Thomas Aquinas. Surely if today's “woke” were as rational as Aquinas, it would be a great improvement.

But there is one sense in which wokeness should be analyzed as a substitute religion, and Dr. Bolotin's lecture gets at it exactly. He detects in today's student radicals a dissatisfaction with the hedonism they have been raised in. "The very permissiveness and absence of high demands that are so characteristic of our modern democracies," he says, "also lead, in some of the young, to discontent and a feeling of emptiness in their lives.” Human beings naturally crave

Helen Andrews is a senior editor at the American Conservative and a graduate of Yale University. 
meaning, which requires belief in something that makes demands, that asks for discipline and sacrifice.

In this, today's youth are like their predecessors in the Sixties counterculture. Think back to the Port Huron Statement: "We are people of this generation, bred in at least modest comfort . .." Tom Hayden's radicalism was a radicalism of affluence. He and his compatriots in Students for a Democratic Society felt that old-fashioned liberal goals, like increasing workers' pay, were obsolete. The challenge now, they felt, was to battle the spiritual emptiness that followed when material wants were satisfied. Hence their focus on personal liberation, things like free speech and free love.

Today's youth are twice as cursed by affluence as the Sixties radicals were, since they enjoy both material abundance and sexual abundance, thanks to those same Sixties radicals. For the average university student today, getting one's fill of sex has become as effortless as getting enough to eat. But far from being a source of deep spiritual meaning, as the hippies predicted, sex has for many become one more empty pleasure.

The only joys that do not pall, the way that permissiveness has made hedonistic pleasures pall, are those that by their nature will never be effortless. Religion is one. Liberal education is another. The classics of the Western canon will always make demands on their readers. Their greatness is a standing rebuke to our mediocrity and an invitation to self-improvement. Perhaps today's student radicals are so zealous in their attacks on liberal education because they detect in it an answer to the very longings that their radicalism promises to satisfy but never will, no matter how stringent they make its ideological demands.

Demanding rules have to be oriented toward a higher goal, otherwise it's just pointless torture. There has to be some end state in mind. The difference between genuine religions and false substitutes is that the former can point to saints whereas the latter can only point to utopias. Saints are the best evangelists that a religion can have, better than preachers or apologists, because saints say by their example: follow my creed and you, too, could someday have this radiant serenity. Utopias say: follow my creed and we could all live in perfect harmony. The difference is that saints exist (there is at least one within fifty miles of you right now, I guarantee) and utopias don't.

Woke activism does make demands of its adherents, so it is superficially attractive to our meaning-starved youth in that sense, but the sacrifices that a 
person pours into wokeness never add up to anything. It doesn't produce people whose excellent personal qualities are an advertisement for their creed. In other words, wokeness produces no saints.

But liberal education does. The positive effects of liberal education are visible. Its sacrifices do add up to something: wisdom. Encountering wisdom in a liberally educated person is like encountering sanctity in a saint. It is a visible testament to the worthiness of the path that person has followed. That visibility is what makes liberal education a target of woke activists, who are jealous because their creed doesn't produce any equivalent benefit that outsiders can see with their own eyes-but it is also what makes it a beacon for all those seeking a path out of our current muddle. 